\title{
Incidence trends and patterns of breast cancer in Sri Lanka: an analysis of the national cancer database
}

\author{
Ashan Fernando ${ }^{1}$, Umesh Jayarajah¹, Saumyakala Prabashani ${ }^{1}$ Eshani A. Fernando ${ }^{2}$ and Sanjeewa A. Seneviratne ${ }^{1 *}$
}

\begin{abstract}
Background: A gradual decline in the incidence of breast cancer is documented in developed countries especially over last two decades, while in developing countries the incidence continues to rise. We conducted this study to examine trends in incidence of breast cancer in a developing country, Sri Lanka.

Methods: A retrospective cohort evaluation of patients with breast cancer during 2001-2010 was performed using population based data from the Sri Lanka National Cancer Registry. Trends in incidence were analysed using Joinpoint regression analysis.

Results: The age standardized incidence of female breast cancer in Sri Lanka appears to have increased from 17.3 per 100,000 in 2001 (95\% confidence interval [95\% Cl] 16.5-18.2) to 24.7 per 100,000 in 2010 (95\% Cl 23.7-25.7); a 1.4-fold increase $(p<0.05)$ with an estimated annual percentage change (EAPC) of 4.4 ( $95 \% \mathrm{Cl} 3.3-5.5)$. Highest incidence of breast cancer was seen among women of 60 to 64-year age group which has increased from 68.1 to 100.2 per 100,000 over this period (EAPC 4.6\%, 95\% Cl 3.9-5.2, $p<0.001$ for trend). A substantially greater increase was observed among women older than 50 years (from 50.4 to 76.9 per 100,000; EAPC 5.5, 95\% Cl 4.1-7.0, $p<0.05$ ) compared with women younger than 50 years (from 32.0 to 39.6 per 100,000; EAPC 2.3, 95\% Cl 1.1-3.5, $p<0.05$ ).

Conclusions: A gradual but a significant increase in the incidence of female breast cancer is observed in Sri Lanka. A rapid rise in the breast cancer incidence among post-menopausal women appears to be the major contributor towards this increase. Improving cancer data collection appears to have been a contributor to the observed increase. However, an inherent increase is also likely as differential rates of increase were observed by age groups. Further research is needed to identify the reasons for the observed increase which may help with future cancer control efforts in Sri Lanka.
\end{abstract}

Keywords: Breast cancer, Incidence

\section{Background}

Breast cancer is the most common cancer affecting women worldwide [1]. Over the last several decades, the incidence of breast cancer has risen globally [2,3] and this is estimated to increase by another $25 \%$ by year 2020 [4]. Studies have shown that the greatest increase will be among women in developing countries, a majority of whom live in the Asian region $[4,5]$. In India alone, over 100,000 new cases of breast cancer are estimated to

\footnotetext{
*Correspondence: sanjeewa@srg.cmb.ac.lk

'Department of Surgery, Faculty of Medicine, University of Colombo, Kynsey Road, Colombo 08, Sri Lanka

Full list of author information is available at the end of the article
}

be diagnosed annually [6]. According to data from the International Agency for Research on Cancer (IARC), a disproportionately high number of breast cancer deaths occur in developing countries due to lower cancer specific survival rates [4]. Most studies on incidence and trends in incidence of breast cancer have been conducted in developed countries, while analyses of these trends and patterns in developing countries including Sri Lanka are limited.

Mammographic breast cancer screening has contributed significantly towards the reduction in breast cancer mortality observed in developed countries where population based screening programmes are in operation [7]. However, the same has contributed to an increase in 
the incidence of breast cancer as many cancers which otherwise would not have manifested clinically, are diagnosed through screening [8]. Many developing countries including Sri Lanka does not have a national breast cancer screening programme. This probably is one reason for the higher proportion of advanced breast cancers at diagnosis observed in Sri Lanka, compared with developed countries [9]. On the other hand, lack of a national screening programme has likely contributed to the lower breast cancer incidence in Sri Lanka compared with the developed countries.

Since 1985, Sri Lanka National Cancer Control Programme (NCCP) has been collecting nationwide cancer data. Over this period, the coverage has gradually increased, and as of 2014 it is estimated to include over $80 \%$ of all cancers diagnosed in the country $[10,11]$. NCCP data include all cancers treated at national cancer treatment centres and data from other major private and government hospitals, and pathology laboratories. As adjuvant treatments in the public sector are instituted almost exclusively through national cancer treatment centres, the overall coverage for breast cancer is likely to be greater than $80 \%$.

This study was conducted with the aim of identifying recent trends in breast incidence Sri Lanka, and to compare these tends with other countries.

\section{Methods}

Details of all patients with newly diagnosed primary breast cancer between 01/01/2001 and 31/12/2010 were extracted from cancer incidence data of Sri Lanka published by the NCCP [12].

Age standardized rates of breast cancer per 100,000 population were calculated for each year using World Health Organization (WHO) age standardized populations [13]. Similar methods were used to calculate age group specific and gender specific incidence rates of breast cancer for each year under consideration.

Significance of the trends in incidence and annual changes in incidence rates were analysed using Joinpoint software [14]. Joinpoint regression analysis identifies points where a statistically significant change over time in linear slope of the trend occurred. This analysis starts with the minimum number of joinpoints, and tests whether one or more joinpoints are statistically significant, and are added to the model. Joinpoint tests of significance use a Monte Carlo permutation method [15]. In the final model, each joinpoint indicates a statistically significant change in trend, and an estimated annual percentage change (EAPC) computed for each of those trends by means of generalized linear models assuming a Poisson distribution. Significance of the change in rates were calculated with $p$ values and $p$ values $<0.05$ were considered as statistically significant.
Joinpoint software version 4.3 was used for Joinpoint regression analysis [14].

\section{Results}

This study analysed a total of 19,755 patients with newly diagnosed primary invasive breast cancer over the 10-year study period. Approximately $98 \%(n=19,291)$ were females and $2 \%(n=464)$ were males. The female to male ratio was 41.7: 1 .

The overall mean age of the patients was 53.1 years (median 52 years). Males were significantly older compared with females at diagnosis (males 58.7 vs. females 52.9 years, $p<0.001$ ). Invasive ductal carcinoma was the commonest reported histological type $(79.3 \%, n=15,341)$ followed by lobular carcinoma in 3.6\% $(n=721)$. Rare variants of breast cancer were reported in $5.7 \%(n=1124)$ patients, while specific histological variant was not documented in $11.4 \%(n=2244)$ patients. The highest incidence of female breast cancer was seen in 60-64 age group (70.3 per 100,000 population), while the highest incidence of male breast cancer was seen in over $75+$ year age group (3.38 per 100,000 population) (Fig. 1).

The WHO age standardized incidence of breast cancer in Sri Lanka was observed to have increased from 9.2 per 100,000 in 2001 (95\% confidence interval [95\% CI] 8.17-9.62) to 12.9 per 100,000 in 2010 (95\% CI 12.4-13.5); a 1.4-fold increase, ( $p<0.05$ for trend) (Fig. 2). This increase translates into an estimated annual percentage change (EAPC) in incidence of 4.4 (95\% CI 3.3-5.4) over this 10-year period. The EAPC for females was 4.4 ( $95 \% \mathrm{CI}$ $3.3-5.5, p<0.001$ for trend) and for males it was 3.1 (95\% CI -2.5-9.1, $p>0.05$ for trend).

Results of the Joinpoint analysis of incidence time trends by age, gender and histology type are shown in Table 1. The EAPC for overall female age standardized incidence rate was 4.4 (95\% CI 3.3-5.5) which was similar to the overall EAPC rate. A greater part of the increase in breast cancer incidence is attributable to an increase in incidence of ductal carcinoma which has increased from 7.2 to 11.3 per 100,000; a 1.56-fold increase $(\mathrm{EAPC}=5.2,95 \%$ CI 2.8-7.8, $p<0.05$ for trend) (Table 1). In comparison, the increase in incidence of lobular carcinoma was observed to be minimal (EAPC $=2.6, p>0.05$ ). Progressively increasing EAPCs were observed with advancing age. EAPC was significantly higher among women older than 60 years $($ EAPC $=5.55)$ compared with women of 40-59 (EAPC $=3.09)$ and $20-39($ EAPC $=2.12)$ year age groups. Furthermore, only a modest increase in the incidence of breast cancer was observed among women younger than 50 years (from 32.0 to 39.6 per 100,000; $\mathrm{EAPC}=2.3$, 95\% CI 1.1-3.5, $p<0.05$ ), while the increase was substantially greater among women older than 50 years (from 50.4 to 76.9 per 100,000 ; EAPC $=5.5$, 95\% CI 4.1-7.0, $p<0.05$ ) (Fig. 3). 


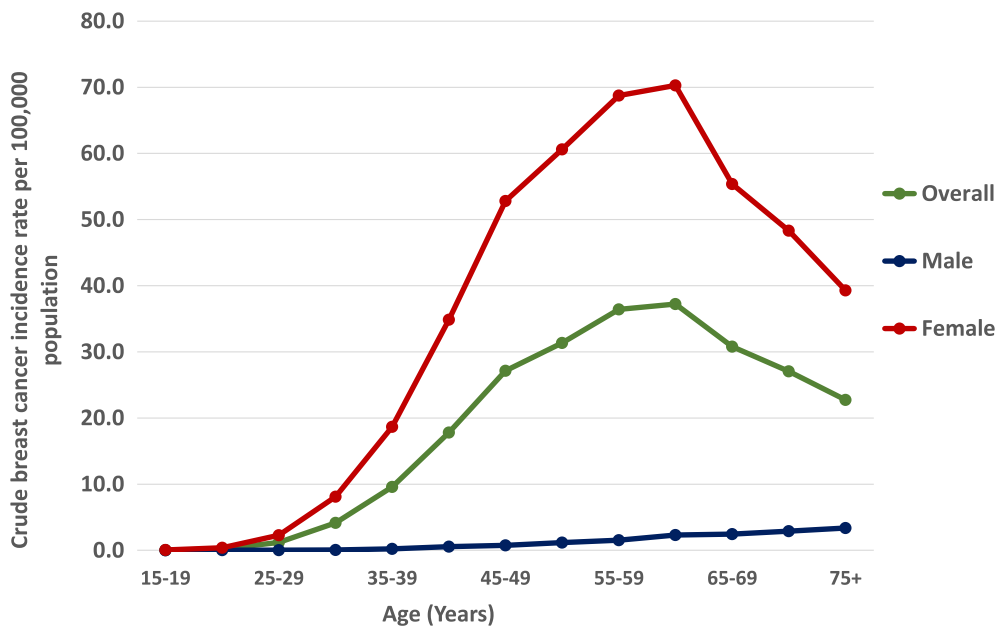

Fig. 1 Crude breast cancer incidence rates by age group in Sri Lanka, 2001-2010

\section{Discussion}

This study based on data from the Sri Lanka National Cancer Registry (SLCR) appears to show a steady increase in the incidence of female breast cancer. The incidence in males has remained largely static. Further, the breast cancer incidence appeared to be rising more rapidly among post compared with pre-menopausal women.

Sri Lanka has a free public health care system, although private health systems which run parallel make a substantial contribution [16]. The burden of cancer care rests almost exclusively with the public sector due to high cost of cancer care which is beyond the affordability of most average Sri Lankans [17]. Hence, studying the incidence patterns of breast cancer is important for the government to make policy decisions on allocating funds and other resources for early detection and treatment of breast cancer.

In general, there has been a gradual and a uniform increase in the incidence of breast cancer over the study period, although a slight drop in the incidence is observed in 2007 (Fig. 2). This is likely to be due to a change in criteria adopted by the NCCP for cases to be included in the cancer registry. Prior to 2007 all invasive as well as insitu neoplasms (ductal and lobular carcinoma in-situ) were included in the registry, while from 2007 onwards only invasive neoplasms are included. Exclusion of in-situ cancers post-2007 may have contributed to an underestimation of the actual increase in breast cancer incidence.

The observed increase in incidence is likely to be due to many factors which include improvement of the coverage of the national cancer data, increase in diagnosis due to breast cancer screening and a true increase in the incidence. Coverage of SLCR has gradually increased overtime with a current coverage rate of over $80 \%$. Number of sources through which the national cancer registry collects data has gradually increased over the study period helping to improve the proportion of cancers reported to the registry [12]. However, even between the years where the data sources to the registry have remained constant (i.e 2004-2005 and 2008-2009), an increase in the incidence could be observed [12].

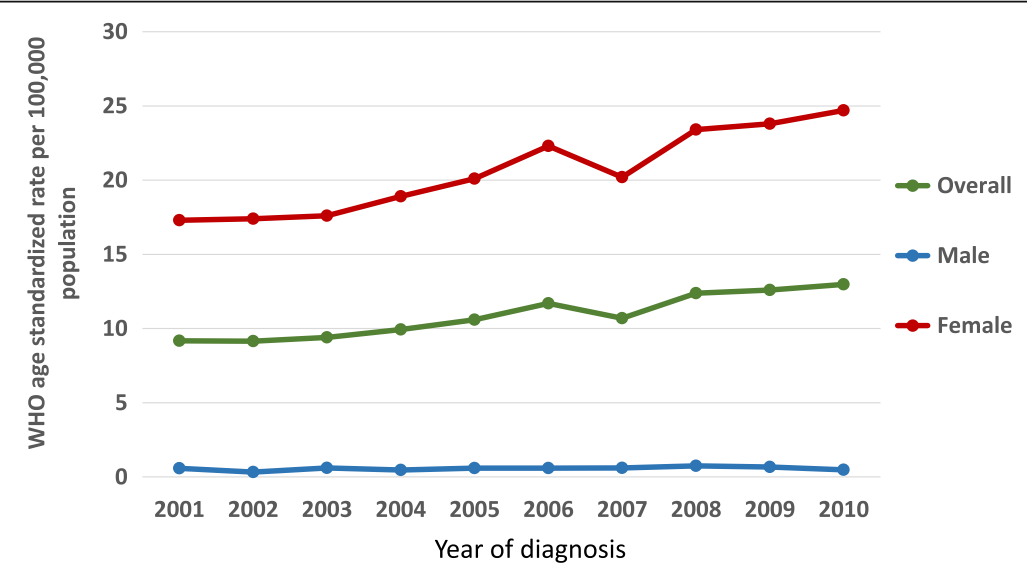

Fig. 2 WHO age standardized incidence rates for breast cancer per 100,000 population in Sri Lanka 2001-2010 
Table 1 Breast cancer incidence in Sri Lanka by gender and age group with Joinpoint analysis of Estimated Annual Percentage Change (EAPC) from 2001 to 2010

\begin{tabular}{|c|c|c|c|c|c|}
\hline & \multicolumn{2}{|l|}{2001} & \multicolumn{2}{|l|}{2010} & \multirow[t]{2}{*}{ EAPC 2001-2010 (95\% CI) } \\
\hline & $\mathrm{n}$ & Rate $(95 \% \mathrm{Cl})$ & $n$ & Rate $(95 \% \mathrm{Cl})$ & \\
\hline \multicolumn{6}{|l|}{ Age group (years) } \\
\hline \multicolumn{6}{|l|}{ Male } \\
\hline$<20$ & 1 & 0.03 & 1 & 0.03 & 0 \\
\hline 20-39 & 2 & 0.07 & 2 & 0.06 & -1.43 \\
\hline $40-59$ & 15 & 0.72 & 10 & 0.44 & -3.89 \\
\hline $60+$ & 26 & 3.16 & 26 & 2.88 & -0.89 \\
\hline Age standardized & 44 & $0.58(0.41-0.76)$ & 39 & $0.48(0.33-0.63)$ & $3.1(-2.5-9.1)$ \\
\hline \multicolumn{6}{|l|}{ Female } \\
\hline$<20$ & 2 & 0.06 & 2 & 0.06 & 0 \\
\hline $20-39$ & 197 & 6.42 & 263 & 7.78 & $2.12^{*}$ \\
\hline $40-59$ & 952 & 44.6 & 1374 & 58.4 & $3.09^{*}$ \\
\hline $60+$ & 396 & 48.1 & 755 & 74.8 & $5.55^{*}$ \\
\hline Age standardized & 1547 & $17.3(16.5-18.2)$ & 2401 & $24.7(23.7-25.7)$ & $4.4(3.3-5.5)^{*}$ \\
\hline Overall age standardised rate & 1591 & $9.17(8.17-9.62)$ & 2440 & $13.0(12.5-13.5)$ & $4.4(3.3-5.4)$ \\
\hline \multicolumn{6}{|l|}{ Histology type } \\
\hline \multicolumn{6}{|l|}{ Female } \\
\hline Ductal CA & 1221 & $13.6(12.9-14.4)$ & 2085 & $21.4(20.5-22.4)$ & $5.2(2.8-7.8)^{*}$ \\
\hline Lobular CA & 74 & $0.8(0.6-1.0)$ & 55 & $0.6(0.4-0.7)$ & $-3.3(-10.4-19.2)$ \\
\hline Malignancy NOS & 158 & $1.8(1.5-2.1)$ & 142 & $1.5(1.2-1.7)$ & $-0.9(-10.6-9.9)$ \\
\hline Others & 94 & $1.0(0.8-1.3)$ & 119 & $1.2(1.0-1.5)$ & $2.4(-2.4-7.5)$ \\
\hline \multicolumn{6}{|l|}{ Male } \\
\hline Ductal CA & 32 & $0.43(0.28-0.58)$ & 33 & $0.41(0.27-0.55)$ & $3.2(-3.3-10.3)$ \\
\hline Lobular CA & 2 & $0.02(0.00-0.06)$ & 0 & 0.0 & - \\
\hline Malignancy NOS & 4 & $0.05(0.00-0.10)$ & 3 & $0.04(0.02-0.08)$ & $5.6(-12.1-26.9)$ \\
\hline Others & 6 & $0.08(0.02-0.14)$ & 3 & $0.03(0.00-0.07)$ & $-4.3(-20.3-15.1)$ \\
\hline \multicolumn{6}{|l|}{ Overall } \\
\hline Ductal CA & 1253 & $7.21(6.82-7.64)$ & 2118 & $11.2(10.8-11.7)$ & $5.2(2.8-7.7)^{*}$ \\
\hline Lobular CA & 76 & $0.44(0.34-0.54)$ & 55 & $0.29(0.21-0.36)$ & $2.6(-10.4-17.6)$ \\
\hline Malignancy NOS & 162 & $0.95(0.82-1.13)$ & 145 & $0.78(0.65-0.90)$ & $-0.8(-10.8-10.3)$ \\
\hline Others & 100 & $0.57(0.46-0.68)$ & 122 & $0.66(0.54-0.78)$ & $2.8(-2.5-8.3)$ \\
\hline
\end{tabular}

*The EAPC is significant $(p<0.05)$

At the same time, it is likely that there has been a true increase in the number of cancers diagnosed in the country. This again is due to multiplicity of reasons. First, there has been a gradual increase in mammographic screen detected breast cancer in Sri Lanka [18]. Although Sri Lanka does not have a national breast cancer screening programme, many government and private institutions have started providing opportunistic breast cancer screening especially over the last decade [19]. This has gradually increased the proportion of screen detected breast cancer which probably has contributed to the increasing incidence.

Despite all these possible reasons for an 'artificial' increase in the incidence, it is likely that there has been a genuine increase in the incidence similar to many other developing countries [1]. Several factors have been proposed to be possible contributors towards this increase. These include westernization of lifestyle including increased consumption of processed and fatty food, sedentary lifestyle leading to increased obesity, delay in childbearing and reduced rates and duration of breast feeding [20]. Recently concluded WHO non-communicable disease risk factor survey 2015 reported the percentage of Sri Lankan females aged 18-69 who were obese to be $8.4 \%$ compared to $5.9 \%$ in 2006 [21]. In the present study, a significantly greater increase in the incidence of breast cancer was observed among post compared with premenopausal women. This 

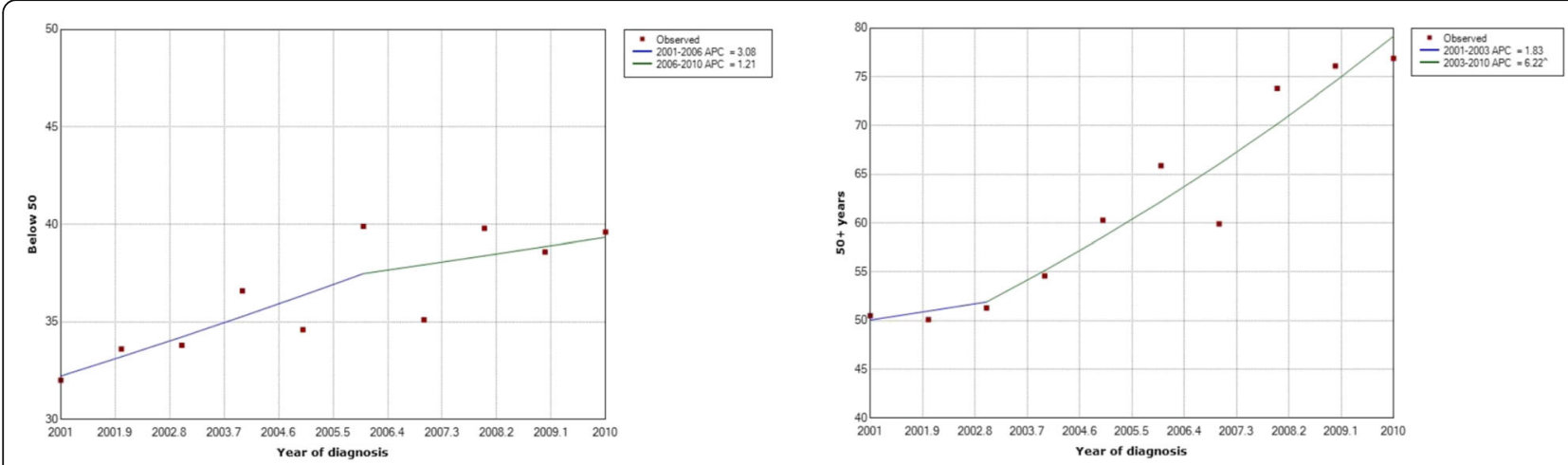

Fig. 3 Joint point trend graphs for breast cancer incidence by age below and above 50 years at diagnosis of breast cancer in Sri Lanka 2001-2010

age specific increase in incidence in older women suggest the possibility of a true increase in incidence, as general registry improvements are expected to have affected all ages similarly. Furthermore, in a similar national cancer database analysis on thyroid cancers in Sri Lanka, no differences in age specific increase in incidence was not observed, which further strengthens the argument that the age specific increase in incidence in breast cancer is due to a true increase [11].

The increase in incidence of breast cancer in older women highlights the impact of obesity on rising incidence of breast cancer as rates of obesity are much greater among post than premenopausal women in Sri Lanka [21]. In addition, the percentage of females not meeting WHO recommendations on vigorous physical activity for health was $89.2 \%$ in 2015 . Late age at first birth and lower fertility which are factors proven to increase the risk of development of breast cancer have also been on the rise [22]. All these have likely have contributed to increase the risk of woman developing a breast cancer and thereby towards the increasing breast cancer incidence.

Sri Lanka has one of the fastest ageing populations in the world [23]. This trend will exponentially increase the numbers of breast cancer especially among older women. Older women are more likely to have more comorbidities and a poorer survival from breast cancer [24]. On the other hand, this increase among older age groups may reflect different rates in adoption of opportunistic breast cancer screening in Sri Lanka. However, evidence from other countries suggest that participation in opportunistic mammographic screening is greater in women younger than 50 years, compared with older women [25]. Regardless, healthcare policy makers in the country need to consider all these factors in planning strategies, if they are to effectively deal with the increasing burden of breast cancer in the country.

There were several limitations in this study. First, the coverage of breast cancer data collection has increased gradually over the study period which likely has contributed to the observed increase in the breast cancer incidence. Another possible limitation of incidence data gathered from 2001 to 2010 includes the civil war in the Northern and Eastern parts of the country (1983-2009). During this period access to health care would have not been uniform in these parts of the Island and the number of breast cancers that reported may not have been accurate. Further, cancer staging data records of NCCP were not complete up to 2007, which prevented us from performing a meaningful analysis of trends in breast cancer stage at diagnosis in Sri Lanka. Analysing the trends in stage distribution would have helped to better evaluate the trends in stage at diagnosis and effectiveness of the strategies to promote early detection of breast cancer. NCCP data did not include many other important information that would have helped to identify possible reasons for the observed trends in incidence. For instance, tumour biological characteristics including receptor status, body mass index, method of detection, menopausal status and other established breast cancer risk factors were not available in the NCCP database. Collection of such information in the future may help better understand the reasons for observed increases in incidence.

\section{Conclusion}

A gradual increase in the incidence of female breast cancer by approximately $4 \%$ per year is observed in Sri Lanka. A rapid rise in the breast cancer incidence among postmenopausal women appear to be the major contributor towards this increase. As Sri Lanka has one of the fastest ageing populations this trend is likely to increase the number of breast cancers among older women exponentially. Healthcare policy planners need to be aware of these trends to effectively tackle the increasing burden of breast cancer in the country. Future research needs to focus on identifying reasons for the observed increase to guide effective cancer control measures. 


\section{Abbreviations}

$\mathrm{Cl}$ : Confidence interval; EAPC: Estimated annual percentage change; NCCP: National cancer control programme; WHO: World health organization

\section{Acknowledgements}

This study was presented at the Annual Congress of the College of Surgeons held in Kandy, Sri Lanka in 2017 [26].

\section{Availability of data and materials}

Data used in this analysis is available online from the National Cancer Control Programme Sri Lanka - http://www.nccp.health.gov.lk/.

\section{Authors' contributions}

AF analysed data and wrote the first version of the manuscript, UJ helped with data analysis and provided comments on the manuscript, SP helped with data analysis and helped with the first version of the manuscript, EAF provided data, advised on analysis and provided comments on the manuscript, SAS conceived the idea, supervised data analysis and wrote the final version of the manuscript. All authors read and approved the final manuscript.

\section{Ethics approval and consent to participate}

Ethics approval for this study was obtained from the Ethics Review Committee of the Faculty of Medicine, Colombo, Sri Lanka (Ref. No. EC-16-206). As only anonymised previously collected data were obtained from the National Cancer Registry for analyses, no patient consent process was involved.

\section{Competing interests}

The authors declare that they have no competing interests.

\section{Publisher's Note}

Springer Nature remains neutral with regard to jurisdictional claims in published maps and institutional affiliations.

\section{Author details}

'Department of Surgery, Faculty of Medicine, University of Colombo, Kynsey Road, Colombo 08, Sri Lanka. ${ }^{2}$ National Cancer Control Programme, Ministry of Health, Colombo, Sri Lanka.

Received: 13 June 2017 Accepted: 18 April 2018

Published online: 27 April 2018

\section{References}

1. GLOBOCAN 2012 v1.0, Cancer Incidence and Mortality Worldwide [http:// globocan.iarc.fr/].

2. Kimmick G, Anderson R, Camacho F, Bhosle M, Hwang W, Balkrishnan R. Adjuvant hormonal therapy use among insured, low-income women with breast cancer. J Clin Oncol. 2009:27(21):3445-51.

3. Porter P. "westernizing" women's risks? Breast cancer in lower-income countries. N Engl J Med. 2008;358(3):213-6.

4. Khokhar A. Breast cancer in India: where do we stand and where do we go? Asian Pac J Cancer Prev. 2012;13(10):4861-6.

5. Anuar NS, Zahari SS, Taib IA, Rahman MT. Effect of green and ripe Carica papaya epicarp extracts on wound healing and during pregnancy. Food Chem Toxicol. 2008:46(7):2384-9.

6. Agarwal G, Pradeep P, Aggarwal V, Yip C-H, Cheung PS. Spectrum of breast cancer in Asian women. World J Surg. 2007;31(5):1031-40.

7. Marmot M, Altman G, Cameron DA, Dewar JA, Thompson SG, Wilcox M. Independent UK panel on breast Cancer screening replies to Michael Baum. BMJ. 2013;346:f873.

8. Bleyer A, Welch HG. Effect of three decades of screening mammography on breast-cancer incidence. N Engl J Med. 2012;367(21):1998-2005.

9. Perera N, Amarasinghe I, Wijesundara N. Establishing a breast clinic in a developing country: effect of a collaborative project. European Journal of Surgical Oncology (EJSO). 2004;30(3):229-32.

10. Jayasekara H, Rajapaksa LC, Brandberg Y. Measuring breast cancer-specific health-related quality of life in South Asia: psychometric properties of the Sinhala version of the EORTC QLQ-BR23. Qual Life Res. 2008:17(6):927-32.

11. Jayarajah U, Fernando A, Prabashani S, Fernando EA, Seneviratne SA. Incidence and histological patterns of thyroid cancer in Sri Lanka 2001-2010; an analysis of national cancer registry data. BMC Cancer. 2018;18:163.
12. National Cancer Control Programme Sri Lanka. Cancer Incidence Data, Sri Lanka 2001-2010. In: Ministry of Health; 2016.

13. Ahmad OB, Boschi-Pinto C, Lopez AD, Murray CJ, Lozano R, Inoue M. Age standardization of rates: a new WHO standard. Geneva: World Health Organization. 2001;9:10.

14. Joinpoint Regression Program V. Statistical Methodology and Applications Branch. In: Surveillance Research Program. USA.; May: National Cancer Institute; 2017.

15. Kim H-J, Fay MP, Feuer EJ, Midthune DN. Permutation tests for joinpoint regression with applications to cancer rates. Stat Med. 2000;19(3):335-51.

16. Jayasekara RS, Schultz T. Health status, trends, and issues in Sri Lanka. Nursing \& health sciences. 2007;9(3):228-33.

17. Steinbrook R. Closing the affordability gap for drugs in low-income countries. N Engl J Med. 2007;357(20):1996-9.

18. Feuer EJ, Wun L-M. How much of the recent rise in breast cancer incidence can be explained by increases in mammography utilization? A dynamic population model approach. Am J Epidemiol. 1992;136(12):1423-36.

19. Nilaweera R, Perera S, Paranagama N, Anushyanthan A. Knowledge and practices on breast and cervical cancer screening methods among female health care workers: a Sri Lankan experience. Asian Pac J Cancer Prev. 2012;13(4):1193-6.

20. Bray F, McCarron P, Parkin DM. The changing global patterns of female breast cancer incidence and mortality. Breast Cancer Research. 2004;6(6):229.

21. Department of Census and Statistics. Census of Population and Housing. In: Edited by Ministry of Finance and Planning, vol. 1. Colombo: Government of Sri Lanka; 2012. p. 103-4.

22. Langford C: Fertility decline in Sri Lanka: could fertility now be at about replacement level? 2001.

23. Abeykoon A. Ageing and the health sector in Sri Lanka. Ceylon Med J. 2015:45(2):54

24. Ferlay J, Soerjomataram I, Dikshit R, Eser S, Mathers C, Rebelo M, Parkin DM, Forman D, Bray F. Cancer incidence and mortality worldwide: sources, methods and major patterns in GLOBOCAN 2012. Int J Cancer. 2015;136(5):E359-86.

25. Borras J, Guillen M, Sanchez V, Junca S, Vicente R. Educational level, voluntary private health insurance and opportunistic cancer screening among women in Catalonia (Spain). Eur J Cancer Prev. 1999;8(5):427-34.

26. Fernando A, Jayarajah U, Senevirathne S, Prabhashani S. Trends in incidence and stage at diagnosis of breast cancer in Sri Lanka. Sri Lanka Journal of Surgery. 2017:35(S1):1.

\section{Ready to submit your research? Choose BMC and benefit from:}

- fast, convenient online submission

- thorough peer review by experienced researchers in your field

- rapid publication on acceptance

- support for research data, including large and complex data types

- gold Open Access which fosters wider collaboration and increased citations

- maximum visibility for your research: over $100 \mathrm{M}$ website views per year

At BMC, research is always in progress.

Learn more biomedcentral.com/submissions 